\title{
Proceedings of a Syymposium on Our Nuclear Future: Delay or Demise?
}


(C) Academy of Science of South Africa

IBSN 978-0-9922286-5-1

September 2014

Published by:

Academy of Science of South Africa (ASSAf)

PO Box 72135, Lynnwood Ridge, Pretoria, South Africa, 0040

Tel: +27 123496600 • Fax: +27865769520

E-mail: admin@assaf.org.za

Reproduction is permitted, provided the source and publisher are appropriately acknowledged.

The Academy of Science of South Africa (ASSAf) was inaugurated in May 1996. It was formed in response to the need for an Academy of Science consonant with the dawn of democracy in South Africa: activist in its mission of using science and scholarship for the benefit of society, with a mandate encompassing all scholarly disciplines that use an open-minded and evidence-based approach to build knowledge. ASSAf thus adopted in its name the term 'science' in the singular as reflecting a common way of enquiring rather than an aggregation of different disciplines. Its Members are elected on the basis of a combination of two principal criteria, academic excellence and significant contributions to society.

The Parliament of South Africa passed the Academy of Science of South Africa Act (Act 67 of 2001), and the Act came into force on 15 May 2002. This made ASSAf the only academy of science in South Africa recognised by government and representing the country in the international community of science academies and elsewhere.

This report reflects the proceedings of the symposium on Our Nuclear Future: Delay or Demise? hosted by the Academy of Science of South Africa on 15 April 2014 at the Innovation Hub in Pretoria.

Views expressed are those of the individuals and not necessarily those of the Academy nor a consensus view of the Academy based on an in-depth evidence-based study. 


\section{PROCEEDINGS OF A SYMPOSIUM ON OUR NUCLEAR FUTURE: DELAY OR DEMISE?}

15 April 2014 


\section{TABLE OF CONTENTS}

\section{SESSION ONE: ENERGY PLANNING AND NUCLEAR ENERGY IN} SOUTH AFRICA

(Chair: Prof Rob Adam, AVENG Group)

- Opening and Welcome Remarks (Prof Daya Reddy, ASSAf) 4

- Integrated Resource Plan Context and Update (Mr Keith Bowen, Eskom)

- Costs, Financing, Timing and Risk Management of Nuclear Power (Prof Harald Winkler, Director, Energy Research Centre, University of Cape Town )

- Perspective on IRP Update (Facilitated Panel Discussion)

- Mr Dennis Britz (Arcelor Mittal, Energy Intensive User Group of Southern Africa)

- Mr Saliem Fakir (World Wildlife Foundation)

- Mr Andrew Kenny (Environmentalist and Consulting Engineer)

- Discussion: Q\&A

- Nuclear Energy and the NDP (Prof Anton Eberhard, Graduate School of Business, University of Cape Town)

- Comparative Costs of Nuclear and Coal-based Power (Dr Dawid Serfontein, School of Mechanical and Nuclear Engineering, North-West University)

- Facing Up to Uncertainty in the Power Sector: The Impact on Technology Choice and Investment Decision-making (Dr Grové Steyn, Meridian Economics)

SESSION TWO: OUR NUCLEAR FUTURE IN THE CONTEXT OF INTERNATIONAL DEVELOPMENTS

(Chair: Prof Anton Eberhard, University of Cape Town)

- International Trends in Nuclear Power Investment and Costs (Prof Tomas Kåberger, Chalmers University, Sweden)

- The Case for Nuclear Power (Prof Philip Lloyd, Energy Institute, Cape Peninsula University of Technology)

- Discussion: Q\&A

- Facilitated Discussion on South Africa's Nuclear Energy Future

- Recap and Closure (Prof Daya Reddy, ASSAf) 


\section{SESSION ONE:}

\section{ENERGY PLANNING AND NUCLEAR ENERGY IN SOUTH AFRICA \\ (CHAIR: PROF ROB ADAM, AVENG GROUP)}

\section{Opening and Welcome Remarks (Prof Daya Reddy, ASSAf)}

Prof Reddy welcomed everyone to the symposium.

While there was much to be debated in the context of South Africa's energy policy, the nuclear aspects of those policies were amongst the most contentious and were argued in committees and among policymakers, academics, researchers, advisors, and in the press and the media. Relevant South African policies and plans included the National Development Plan (NDP) and the government's Integrated Resource Plan (IRP) for electricity. What was needed was a current and comprehensive view in a highly dynamic context and situation, together with policy and other means to make firm decisions and to act on those decisions.

ASSAf had a role to play in informing the processes that would lead to such decision-making and policy development. The Academy was recognised through an Act of Parliament as the official science academy of the country. Its Members constitute an independent body of top scholars from the natural and the human sciences. The Academy is committed to mobilising the best intellects, expertise and experience in the country in order to provide and work towards evidence-based solutions to national and regional problems. It has no vested interests and relies on the willingness of its Members and other experts whom it calls upon to provide their services on an entirely voluntary basis. ASSAf's multi-disciplinary nature and its work are characterised by scientifically rigorous analyses of evidence in the best traditions of science. As part of the Academy's brief to promote science awareness and science literacy, it has an important role in helping to ensure that the general public is well informed on issues such as those to be discussed during this symposium. 
Among the projects and activities that have been undertaken by the Academy in the past years, a number were closely related to the topic of this symposium. In 2011, ASSAf hosted a symposium on nuclear safety, followed by the publication of a proceedings report and a statement on nuclear safety, which were widely disseminated. ASSAf carried out a detailed commentary on the IRP 2010 and, after a meeting of African science academies on improving energy access in sub-Saharan Africa, produced a policymakers' booklet that was translated into French and widely disseminated.

The purpose of organising this symposium was to bring together a diverse range of views and invite engagement in a rigorous, evidencebased, scholarly debate on the issue of nuclear energy. This topic has lent itself to serious analysis, but required even more analysis on what should be happening in this country. Panellists, chairs and presenters are from a range of backgrounds: academia, government, private and public sectors, and civil society. This would be the first occasion for some of the participants to debate these issues on the same forum. South Africa is not alone in the world in grappling with the issues related to nuclear energy. The international perspective on nuclear energy would be provided by Prof Thomas Kåberger from Sweden.

\section{Integrated Resource Plan Context and Update (Mr Keith Bowen, Eskom)}

The IRP 2010 was a blueprint of the types of generating capacity that would be required in South Africa over the next few decades. The original IRP 2010 was a widely consulted document, which had come through a very broad process with inputs from various elements of society and expertise. The Department of Energy (DoE) and the Cabinet had reached consensus about the energy mix. The IRP 2010 proposed a radical departure from an almost entirely coal-based generating fleet and introduced renewables, more nuclear and more gas while allowing a place for coal, and set the scene for a very strong change in the country's generating capacity. Changing circumstances (such as new energy finds and political developments) necessitated a process to update the IRP. In updating the IRP, the DoE had run a consultative process, which had drawn comments from a wide range of stakeholders. 
Aspects of the IRP had led to uncertainty in a number of underlying assumptions. The IRP update proposed a series of decision trees instead of a plan in order to provide information that would assist decision-makers in determining the direction to be taken. The most significant change that resulted from the consultation process and policy-adjusted IRP was the increase in renewables, predominantly due to photovoltaic (PV) generation. However, a significant drop in the electricity demand was evident over the previous five years relative to the IRP 2010 expected energy consumption despite the fact that the economy had recovered from the 2009 financial crisis and had grown as expected. An analysis of the situation revealed that pricing of electricity had played an important role in constraining the electricity demand and keeping it at the same level as economic growth into the future, even though supply could not match demand. Changing dynamics caused by higher electricity prices could mean that prices would not revert to the 2005 level when the electricity demand grew in tandem with economic growth. More analysis would be required to determine the demand trajectory over the next 20 years, an important factor in order to assess technology requirements.

The capital cost assumptions used for different technologies showed that the capital costs of nuclear had grown relative to the IRP 2010 in real terms. The capital costs of concentrated solar power (CSP) had also increased, mainly because of a deteriorating exchange rate, while there had been a relative decrease in the capital costs of PV and wind in real terms. One of the biggest divergences of opinion was around future nuclear costs. The IRP 2010 used the Electric Power Research Institute (EPRI) costs of US $\$ 5300 / \mathrm{kW}$. Feedback from many players in the public participation process, including Eskom, indicated that the costs of nuclear would be much higher than originally assumed. Technology choices were dependent on capital costs.

A series of scenarios was considered in relation to demand projections up to 2050. The NDP presented the idea that in order to alleviate poverty and reduce unemployment it would be necessary for the gross domestic product (GDP) to grow by $5.4 \%$ on average over the next 20 years. The IRP update translates this into a $2.8 \%$ average growth in electricity demand.

The role of nuclear as a baseload provider was considered in relation to other baseload technology choices. Nuclear potentially competed 
with technologies such as gas, coal and coal with carbon capture and storage (CCS) that could be dispatched as and when required.

The decision trees indicated the best technology option under different scenarios and highlighted the fact that low demand growth would not require nuclear build until 2035, while higher growth would require nuclear build earlier. Nuclear was less preferred to other technologies if the cost was above US $\$ 6500 / \mathrm{kW}$. Coal options include life extension of the existing fleet, building a large pulverised fuel coal plant in 2029 and building small-scale fluidised-bed combustion coal units.

\section{Costs, Financing, Timing and Risk Management of Nuclear Power}

(Prof Harald Winkler, Director, Energy Research Centre (ERC), University of Cape Town (UCT))

The emphasis in this presentation was on the general issues, such as costs, financing, timing and risks, which should be addressed by any energy technology.

The general issues to be taken into account in the case of nuclear are:

- Costs and financial viability

- Localisation

- Potential developmental benefits

- Environmental costs and benefits

- Transparent policy, plans, procurement and governance

- The planning context with multiple objectives

Specific issues that have to be taken in account in relation to nuclear are:

- Safety

- Storage of high-level radioactive waste

- Siting

The ERC has found the updated IRP to be good technically and the approach of decision-making under uncertainty, rather than a single 'preferred plan', to be sensible. The IRP update effectively indicated that a decision about nuclear would be required only ten years before the highest demand scenario in 2025. 
The ERC had done modelling and published a report Towards a New Power Plan on behalf of the National Planning Commission (NPC). The ERC did not propose a new plan but provided information to inform the update of the IRP, with a focus on energy supply alternatives. The study focused on questions on the supply-side, and did not include an update of detailed bottom-up demand projections. Based on recent events (e.g. global financial crisis), it was assumed that demand would be significantly lower in 2030 than previously expected, as did the IRP update. In terms of the timing of nuclear power, given demand projections and different capital costs, the partial optimisation model indicated that nuclear would be required only from 2040 with lower demand projections and at US\$ $7000 / \mathrm{kW}$ upfront capital costs. New nuclear would be required from 2029 if demand proved to be higher, and if investment costs were US $\$ 5000 / \mathrm{kW}$ or lower.

Flexibility of options was important in the frame in which decisionmaking was approached, as well as in terms of the lead times and increments as there were risks of over-build and under-build. The ERC study assumed the same net real post-tax discount rate of $8 \%$ as the IRP update. A review by Schneider et al. (2013) of the nuclear industry globally found that the average construction time of a nuclear unit was 9.4 years. This figure was used by the ERC.

The levelised cost of energy (LCOE) was an important metric and was a handy tool for comparing the unit costs of different technologies over their economic life. It incorporated capital costs (capex), and operating and maintenance costs (opex) over different lifetimes. The cost structure of the different technology options had to be understood. Coal had lower capex and high opex, nuclear had high capex and lower opex - the latter being a similar cost structure to renewables, which have no fuel costs and thus can have even lower opex. Good practice was to test the sensitivity of cost results with different discount rates. Results from the ERC study in relation to levelised costs showed that imported hydro was very attractive while coal was the domestic technology with the lowest LCOE at high capacity factors (if $\mathrm{CO}_{2}$ considerations were not taken into account). Gas was competitive with nuclear depending on the cost assumptions for nuclear (US $\$ 5000 / \mathrm{kW}$ or US $\$ 7000 / \mathrm{kW}$ ) and on capacity factors. The range for solar thermal plants with assumed 14-hour storage was very close to the nuclear range.

Financing nuclear was an important factor. Public domain cost estimates of a nuclear fleet for South Africa, ranged from R322 to R1 044 
billion and that scale raised questions about financing the programme, particularly in the context of:

- the R225 billion shortfall for Eskom's current build programme;

- government's provision of R350 billion debt guarantee, impacting on the debt to gross domestic product (GDP) ratio;

- the cost of servicing public debt (R115 billion per year), which leaves very little room for further guarantees;

- whether further capex for Eskom would come from debt from capital markets raised against its balance sheet, or from export credit agencies or Russian finance, and what the element of risk would be;

- the timing of the decisions concerning nuclear and changes in costs over time.

Improving energy governance is a key goal of all energy policy, as outlined in our Energy Policy White Paper of 1998. There were questions about transparency in relation to nuclear policy, governance, risk management and the procurement process, and about public information. The history of nuclear power has been secretive globally, given its origins in the military-industrial complex. The way the nuclear policy came about in this country has differed to that of other energy policies. In 2008, when Nuclear 1 was to be built, procurement was run as an internal programme by Eskom. Questions were also raised about whether decisions about nuclear would be based on good technical analysis and evidence-based policymaking, or on geo-political considerations. Given the specific risks of nuclear power, processes should be as, if not more, transparent as any other energy policy, planning or procurement process.

Risk management considerations of nuclear included:

- The expense of over and under-build of power plants to the South African economy and society. Both over and under-investment have very large costs on the economy and society.

- Managing the risk of large 'lumpy investments'. Building $9600 \mathrm{MW}$ was a risky proposition that had upside risks of delays, as well as downside risks of over-build. The approach to making decisions under uncertainty (decision trees) made much sense.

- The building of power generation with smaller unit size had advantages, ameliorating the risk of large plants being built as a nuclear 'fleet'. 


\section{Perspective on IRP Update}

(Facilitated Panel Discussion)

The following questions were posed to the panel:

1) Are predictions of lower growth rates in line with the aspirations for national economy growth or merely self-fulfilling and therefore potentially dangerous?

2) Can South Africa meet its $\mathrm{CO}_{2}$ emission targets based on the updated IRP 2010?

3) The outer years of the IRP (2050) see a South African energy landscape where nuclear and renewables might feature very strongly. What, if anything, is likely to disrupt this?

\section{Mr Dennis Britz}

\section{(Arcelor Mittal, Energy Intensive User Group of Southern Africa)}

The challenge in developing the IRP in South Africa had to do with forecasting and planning within the context of high uncertainty, as well as the historical reliance on coal power. Globally, there were significant changes in the type, origin and availability of primary energy supplies, energy carriers and technologies, as well as new policy environments in terms of energy efficiency, energy resources and climate change mitigation. Although these changes offered much opportunity they also caused uncertainty and therefore risk. Industry, especially energy intensive industry, required assurance in terms of:

- Price: Mining, minerals and manufacturing industries were particularly price sensitive due to their energy intensity and they needed internationally competitive-priced electricity and predictable pricing.

- Security of supply: Supply of electricity had to be reliable and sufficient. Expansion of least cost options of supply had to be in line with national resource planning.

- Technology and mix: Industry had to benefit from all the technologies, the right mix of energy and the natural resources in the region.

All energy types, including nuclear, had a role to play in industry. Timing was critical in order to avoid over-commitment, over-build and under-build. It was necessary to have a plan to build, and to build to 
that plan. The high cost of nuclear per kW installed and the lengthy construction periods associated with nuclear plants presented specific risks to developing countries, particularly in uncertain economic times.

Mr Britz responded as follows to the questions posed to the panel:

1) The GDP energy intensity would keep on reducing due to the increasing price of energy in South Africa and the drive in terms of climate change.

2) There was a fine balance between affordability in terms of price and absolute $\mathrm{CO}_{2}$ targets. If the price was too high there would be no buyers of electricity and the demand would decrease.

3) Factors that could disrupt the 2050 South African energy landscape included the world's view in relation to climate change, natural gas developments in South Africa, and experiences of renewables.

\section{Mr Saliem Fakir (World Wildife Foundation (WWF))}

It was important to explore certain critical questions of relevance to the nature of the energy mix from the WWF's perspective. These questions concerned predictions of the economy over the next ten to 15 years and whether the NDP's projection of $5.4 \%$ growth in GDP would be realisable in the next ten years given the global recession and decreasing growth rates in China and other economies. The level of certainty around the growth rate influenced the demand. Even if demand grew, the level of energy required would not necessarily be at a higher level than predicted in the IRP 2010. There was uncertainty about whether there would be more growth in the energy intensive sectors, particularly given increases in electricity prices and challenges relating to the competitiveness of the sectors. Perhaps the economy would change to include more service, and other less energy intensive, sectors.

WWF's questions about nuclear concerned the following:

- Linking overnight costs to the actual costs of building a nuclear plant, including the potential for cost overruns.

- The levelised cost of running a nuclear plant compared to other technologies, such as gas or renewables.

- The economics of managing spent fuel, decommissioning of plants and dealing with long-term radioactive waste. 
- Liability issues around the cost of the plant and safety issues.

- Uncertainty about economic growth and the need for flexibility of technology options, how to solve the energy problem in the interim, as well as in the long term taking into account evolving technologies, including storage technology.

- The distinction between the economic discount rate and the financial discount rate, and an appropriate choice of discount rates for nuclear and other energy technologies.

\section{Mr Andrew Kenny}

\section{(Environmentalist and Consulting Engineer)}

The gifts of nature must be used respectfully and wisely, and must work in harmony with nature. In the context of energy, wind and solar should be used for small, off-grid applications and nuclear should be used for baseload electricity.

Nuclear was by far the safest source of energy, had the smallest environmental disruption and the least waste. All energy technologies produced waste that lasted for millions of years, while only nuclear had proper procedures for the safe storage of its waste. Nuclear power was always economically competitive and often the cheapest and the most reliable source of energy. Nuclear plants could be situated wherever required. Nuclear accident risks were far lower than the risks of other energy sources. Fukushima was a recent demonstration of nuclear safety, particularly as nobody was, or was likely to be, killed or harmed by the radiation.

The following flaws were identified in the IRP update:

- $1 \mathrm{MW}$ of capacity from wind was treated the same as $1 \mathrm{MW}$ from nuclear, whereas $1 \mathrm{MW}$ of nuclear produced twelve times as much electricity as $1 \mathrm{MW}$ of wind.

- $1 \mathrm{kWh}$ of wind power was treated the same as a kWh of nuclear power. This was untrue because of the intermittency of wind.

- The high price of nuclear was incorrect.

- The load factors of $30 \%$ for wind and $19.4 \%$ for solar PV were inflated. 
- The fundamental fact about $\mathrm{CO}_{2}$ reduction was not recognised. $1 \mathrm{kWh}$ of nuclear displaces $1 \mathrm{kWh}$ of fossil generation and $1 \mathrm{kWh}$ of wind or solar did not displace $1 \mathrm{kWh}$ of fossil generation.

- The projection of a lower electricity demand in the future was incorrect.

The IRP should be re-written to take into account the lessons learnt from Germany's green experiment. In 2011, after nuclear safety had been demonstrated at Fukushima, Germany decided to phase out nuclear power, which had been that country's safest and cheapest source of electricity, and to replace it with wind and solar. The result of this decision was:

- soaring electricity prices, now almost the highest in Europe, responsible for shutting down or relocation of industries;

- unstable electricity with a huge increase in power failures, grid fluctuations, stoppages and damage;

- environmental blight and pollution;

- increased $\mathrm{CO}_{2}$ emissions.

The rich elite has been the only beneficiary of this green revolution. The electricity companies were forced to buy wind and solar electricity at very high prices whether or not it was needed. This represented enormous subsidies to wind and solar power, which deprived the poor as finances were transferred to pay rich developers of wind and solar power plants. Germany spent vast amounts of money on thousands of gigantic wind turbines and huge arrays of PV panels. Wind and solar power have been shown to be unreliable and unpredictable. For example, on a certain day in 2013, German wind with a capacity of $32500 \mathrm{MW}$ produced only $120 \mathrm{MW}$ with a load factor of $0.4 \%$. Other generators, notably gas turbines, were obliged to ramp up and down to compensate for the unpredictability, running inefficiently, using more fuel per kWh and emitting more $\mathrm{CO}_{2}$.

Wind turbines were a massive and a wasteful, inefficient use of earth's resources. They used ten times more concrete and steel per kWh than nuclear plants and caused suffering to people living in proximity, as well as severe environmental problems. Wind power for grid electricity was extremely expensive and completely dependent on subsidies enforced by governments, hopelessly unreliable and had extremely low capacity factors. 
In South Africa solar was much more productive than wind, but was not a viable option for grid electricity or baseload electricity, except concentrated solar power (CSP) with storage, which could be used for peaking power.

According to examples of recent contracts for nuclear, capital costs of US $\$ 4$ 000/kW were reasonable. China and South Korea were building nuclear plants within those countries at under US $\$ 2000 / \mathrm{kW}$. Actual production costs in the US were currently at US $\$ 0.024 / \mathrm{kWh}$ and the real rate of return was reasonable at 3\%, lower than the current Eskom bond yield. These costs would provide nuclear electricity at a commercial price of US $\$ 0.070 / \mathrm{kWh}$.

Statistics South Africa (Stats SA) figures reflecting electricity consumption in South Africa between 1993 and 2013 showed that consumption peaked in 2007/2008 followed by a slump in demand. This 'peak' was not due a sudden change in the economy but was caused by Eskom's inability to meet the growing energy demand, which resulted in load shedding, energy saving, reduced production, cancelled projects and a crippled economy.

For a future growing and healthy economy, South Africa needed huge amounts of extra baseload electricity and this could best be provided by nuclear power.

\section{Discussion: Q\&A}

Mr Alex Tsela: The models presented are evidence-based. Do we have evidence that the lack of energy depresses demand, or does the availability of energy stimulate demand?

Response, Prof Harald Winkler: The general approach in integrated resource planning is that they start with demand. The South African public wants services. This should be the starting point. I am not aware of any evidence that supply generates demand.

Response, Mr Andrew Kenny: There is a huge cost to the economy when there is inability to supply electricity when it is needed.

Response, Mr Dennis Britz: Industry will not invest if there is uncertainty in terms of energy availability. 
Dr Dawid Serfontein: I was perplexed by the chart in Mr Bowen's presentation that showed that electricity demand decreased but the economy grew. My study of the matter showed that the cost of electricity affected the economic sectors differently.

Response, Mr Bowen: When measuring GDP, value-add is measured. Value-add in the secondary and tertiary economies is growing at a faster rate than the value-add from primary economy. Even if electricity is being produced to supply a mine, where many other services are being provided and they are growing at the same level, the valueadd out of these services generally tends to be higher than mining. This has been the case since 2005. It is necessary to bear in mind that GDP represents the value-add and not the physical product. It is necessary to consider that gold mining, the most energy intensive component, has been declining at a steady rate. This means that if other mining is growing, it is not as energy intensive as gold mining and it means that the economy is growing in those areas that have less of an impact on electricity demand. We are not suggesting that mining stops, but that mining is going to be less energy intensive and the other sectors connected to mining will have high value-add.

Dr Kelvin Kemm: South Africa has the same size population as South Korea, and South Korea has double the electricity consumption as South Africa. There must be a reason for this. I cannot see that South Africa is not aiming to double its electricity consumption in a short time.

Mr Dennis Britz: Once industry has certainty on the price going forward and the availability of electricity then we will probably see new investment. Until then, there will be no new investment.

Mr Saliem Fakir: Andrew Kenny's data from Germany are misleading. The debate in Germany is about where the burden of the cost is being transferred. This debate requires more granularity. The cost of electricity in Germany per GDP output has stabilised and in some periods it has decreased. Talking about green technology as adding a burden to the economy is somewhat senseless as the broader benefits of renewable energy need to be taken into account. It is important to provide the proper context.

Response, Mr Andrew Kenny: Figures show that the cost of electricity in Germany has soared since the green revolution. The fact is that people cannot pay their bills and industries are relocating. 
Response, Mr Dennis Britz: In Germany private households are subsidising industry so that industry can survive and grow.

Prof Tomas Kåberger: I do not understand Mr Kenny's statement that a $\mathrm{kWh}$ of nuclear energy displaces $\mathrm{CO}_{2}$ emissions whilst a kWh of renewables would not.

Response, Mr Andrew Kenny: One kWh of wind does not displace one kWh of fossil fuel. The reason is, because of the wild fluctuations in wind and something else has to compensate, and this is usually a gas turbine. Fluctuation means inefficiency and more $\mathrm{CO}_{2}$ being emitted than it otherwise would. The other point is that in order to allow for unpredictable fluctuations in the future there is a much bigger spinning reserve on the grid that also uses up electricity.

Prof Philip Lloyd: In assessing the IRP 2010 and its update, what was the extent to which the risk factors associated with the delivery from the renewable energy side were taken into account? The cost of nuclear versus some of the other technologies is very high.

Response, Mr Dennis Britz: Industry is still waiting for renewables that run 24/7. Industry needs baseload to operate in the country. Nuclear and coal, and hydro if available, are the better options.

Prof Anton Eberhard: Mr Kenny dismissed wind as being too expensive and not providing reasonable amounts of power. Could Mr Bowen report on the experience of the renewable energy independent power producers (IPPs) that have been connected? A number of the wind and solar plants have already been connected and production figures are available. Do you have a sense of what power wind and solar is displacing and its economic value on the system?

Response, Mr Keith Bowen: We had assumed in the model that wind would on average have a $30 \%$ load factor and PV on average $18 \%$. The model has a geographic profile for likely load factors for each of these technologies. The one downside of the model is that it assumes this profile, rather than actual performance, which is a shortcoming that we are working on. In terms of the actual output of renewables thus far, wind on average for February and March 2014 is above 32\% to $33 \%$ load factors for the four sites that are currently operational. We have seen $25 \%$ load factors on average for PV and one site is going up to $34 \%$. 
This shows that the model was conservative for renewables. We have only reported on two or three months and we will have to get at least a year's worth of data to see what happens during different periods of the year. In price terms, the renewable energy IPP programme has delivered wind contracts as low as $66 \mathrm{c} / \mathrm{kWh}$.

\section{Ms Manisha Gulati:}

1) If Fukushima was not a disaster, as Mr Kenny argues, why did the Japanese government undo its nuclear power programme?

2) If wind turbines are an eyesore on the Garden Route, could it be assumed that nuclear power would keep South Africa as one of the top tourist destinations?

\section{Response, Mr Andrew Kenny:}

1) At Fukushima, with the worst possible circumstances, the result was that nobody was killed. This is an extraordinary tribute to nuclear safety.

2) It would take about 3000 wind turbines to produce the same amount of electricity as Koeberg, but they would not be able to replace Koeberg because of unpredictable supply.

Mr Dennis Britz: Industry needs affordability, certainty and predictability.

Mr Saliem Fakir: The WWF is well beyond the polemics about renewables. We have recognised renewables as part of the energy mix and as a serious investment. We must consider the empirical evidence that is emerging with the installation of renewables in terms of cost, capacity factors and so on, and not engage in polemics where incorrect fact and figures are bandied about.

\section{Nuclear Energy and the NDP}

(Prof Anton Eberhard, Graduate School of Business, UCT)

Energy, particularly nuclear energy, involves huge capital requirements, much larger than other infrastructure sectors, and hence technology choices and investment decisions are important public policy issues in South Africa. The decisions that had to be made in the next few years would be crucial in economic terms and in relation to choices about future energy security for the country. 
Energy issues had been addressed in the NDP chapter on infrastructure and the energy vision was informed by economic growth and development, social equity and environmental sustainability, supported by good governance. The diagnostic exercise undertaken by the National Planning Committee (NPC) at the beginning of its work showed that the biggest gain in the energy sector since 1994 had been in access to electricity. Electricity had been reliable and cheap, although arguably at uneconomic prices. Since 2005, security of supply had been under threat and prices had trebled in order to reach more economic levels. The reform process had stalled within the electricity sector and renewable energy remained a minor contributor to supply.

The concerns about security of petroleum supply and storage infrastructure had still not been addressed. Coal was of economic importance and among the three top export earners, yet exports had stagnated because of inadequate rail infrastructure. Domestic use of coal had increased and South Africa had become the $13^{\text {th }}$ largest $\mathrm{CO}_{2}$ emitter globally. Energy intensity (kWh/GDP) had continued to decline since 2007, but incentives and programmes promoting energy efficiency remained modest and haphazard. Energy issues cut across a number of government departments and there was a need for better coordination and more consistent progress.

Some of the key energy proposals in the NDP concerned:

- security of coal supplies to Eskom;

- expansion of coal exports;

- upgrading of oil refineries to Euro5 standards;

- delaying investment in new refineries until warranted by demand;

- development of a gas master plan (liquefied natural gas (LNG) imports, Mozambique pipeline, off-shore, shale);

- procurement of sustainable renewable energy;

- reform of the electricity market and the electricity distribution industry.

The NDP stated the following about nuclear:

- "South Africa needs a thorough investigation of the implications of nuclear energy, including its costs, financing options, institutional arrangements... a potential nuclear fleet will involve a level of investment unprecedented in South Africa. An in-depth investigation into the financial viability of nuclear energy is thus vital"; 
- 'South Africa needs an alternative plan - 'Plan B' - should nuclear energy prove too expensive, sufficient financing be unavailable or timelines too tight. All possible alternatives need to be explored".

The NDP also stated the following about energy planning:

- Energy planning needed to become more holistic and integrated.

- The NPC had engaged with the DoE around both the Integrated Energy Plan (IEP) and the IRP.

- There were concerns that the IEP would be viewed as a rigid master plan, while underplaying the role of the much more detailed and robust sub-sector plans such as the IRP.

- The NPC had commissioned modelling from the ERC in order to catalyse the updating of the IRP.

The broad philosophy underpinning the updated IRP was a sense that decision-making would change as conditions changed, as illustrated in a set of decision trees.

The NPC supported the IRP update proposal that if electricity demand was lower and nuclear prices were above US\$ 6500 then it would be better to use more imported hydro, gas or other options.

Two data points provided an indication of nuclear energy investment costs relating to the latest contracts, namely the Hinkley B nuclear plant in the United Kingdom at an investment cost of US\$ $8150 / \mathrm{kW}$ and a Russian reactor in Hungary at an investment cost of US\$7 031/kW. It was important to understand what these costs include. Ultimately, given the large discrepancies in nuclear cost assumptions it would be prudent to quote figures that came from actual signed contracts and market prices.

The NPC had raised two core concerns around nuclear energy:

\section{- Costs}

- It was important to get more accurate costs, particularly in respect of investment costs.

- The economic impact of cost and time overruns on large capital intensive projects, such as nuclear plants in France and Finland, had been catastrophic. 


\section{- Financing}

- The South African government was not in a position to offer investment capital for nuclear, given the country's fiscal and debt constraints.

- Risk allocation was critical as government and consumers, and not nuclear vendors, could bear the risk if nuclear projects went over time or budget.

The NPC advocated adopting a path of least regret, by:

- adopting dynamic and flexible electricity planning;

- avoiding locking in mega capital-intensive power projects with risks of cost overruns and long and uncertain build times;

- investing in a diverse range of energy sources with shorter lead times that can be brought online incrementally to meet changing electricity demand.

The NPC recognised that a range of energy options was available and viable in South Africa, in particular smaller coal, gas, renewable energy and energy efficiency.

\section{Comparative Costs of Nuclear and Coal-based Power} (Dr Dawid Serfontein, School of Mechanical and Nuclear Engineering, North-West University (NWU))

The IEP and IRP update laid an excellent foundation and presented a very comprehensive set of data and used sophisticated modelling tools. Dr Serfontein reviewed both documents on behalf of the Nuclear Industry Association of South Africa (NIASA) and claimed to have found a number of serious flaws that skewed results to the detriment of nuclear. Similar flaws were also discovered in about $90 \%$ of the nuclear costing studies examined.

The results of modelling done by the NWU in terms of the business case for nuclear indicated that nuclear plants were twice as expensive as coal, but lasted for 60 years instead of 25 to 50 years in the case of coal plants. The cost of capital was the deciding factor in a decision about whether or not to opt for nuclear. The LCOE was calculated as a function of the weighted average cost of capital (WACC), a combination of the interest rate paid on loans and the profit earned. A conservative approach, applying full external (including accident 
evacuation) costs, was taken. The overnight cost was estimated at US\$ $5500 / \mathrm{kW}$ for the expected case and US $\$ 7000 / \mathrm{kW}$ for a pessimistic case, for generation III type reactors. The only external cost for the expected case for coal was R 120/ton $\mathrm{CO}_{2}$ tax. For the pessimistic coal case, the full external costs were taken into account. Excluding the very high health costs of coal was the most serious flaw in the IEP, the IRP and most other studies.

The LCOE, as a function of post-tax WACC demonstrated the dependence of nuclear viability on the cost of capital. It would be too expensive to build nuclear at $8 \%$ WACC. However, Eskom currently borrows money at a real interest rate of just below $3 \%$ and the WACC percentage was similarly regulated by the National Energy Regulator of South Africa (NERSA). At these rates, nuclear power would be cheaper than coal power, even for the pessimistic nuclear case. Coal would be less profitable than nuclear if the electricity selling price (R/kWh) remained low. Government would make a larger profit out of the nuclear plant. If government's intention was to make the maximum nominal profit from Eskom, then it would do best to invest in nuclear. Even if the intention was to supply electricity at the lowest price to industry in order to stimulate growth, nuclear-powered electricity would still be supplied at a lower price than coal power. Unlike other studies, the calculations for the model were based on the full plant life (60 years for nuclear and 50 years for coal). The IEP and IRP made provision for nuclear plants to be built by about 2025 and the model ran until 2050. Only 25 years of the 60-year plant life were reflected in the IEP and the IRP results, grossly underestimating its capacity to reduce $\mathrm{CO}_{2}$ emissions.

In conclusion, new nuclear would produce electricity more profitably than coal if funded with low cost capital. The external cost of new nuclear (R0.005/ $/ \mathrm{kWh}$ ) is about 50 times lower than that of coal (R0.26/ $\mathrm{kWh}$ ). South Africa should therefore deploy nuclear as a long lead time, cheap baseload technology, targeting the minimum expected growth in baseload demand, adding peaking technologies and quickly deployable technologies to address looming shortages in supply, as and when they appear.

The IEP and IRP update used an unrealistically high real discount rate (the IEP used an economic opportunity cost of capital (EOCK) of 11.3\%) and massively underestimated the cost efficiency of nuclear power for 
reducing $\mathrm{CO}_{2}$ emissions. In the IEP, the DoE used a real discount rate of $11.3 \%$, instead of a more realistic $5.3 \%$, which would have produced fundamentally different optimisation results. The IRP update used a WACC of $8 \%$. As technology-specific loan offers from nuclear vendor countries eliminate the opportunity cost of capital for nuclear, it is recommended that a real post-tax WACC/discount rate of $3 \%$ should be used.

More flaws in the IEP and IRP were:

- Intermittency costs of wind and PV solar were not taken into account.

- 'Time of day' electricity selling prices were not taken into account, unfairly benefitting intermittent sources, especially PV.

- Imported $\mathrm{CO}_{2}$ emissions were ignored. This led to the IEP recommendation in some scenarios that South Africa should import $90 \%$ of its energy (petrol, diesel, natural gas and coal and hydro power), which would cause massive local job losses in South Africa and serious problems in the balance of payments, and would threaten national security.

- External costs were not internalised, benefitting coal and gas, but discriminating against nuclear and wind.

The flaws in the IEP and the IRP should be corrected, and thereafter a more cost-effective technology mix will emerge.

\section{Facing Up to Uncertainty in the Power Sector: The Impact on Technology Choice and Investment Decision-making (Dr Grové Steyn, Meridian Economics)}

The task of planning in the energy sector should address optimal technology choices and investment decisions in the face of uncertainty. Superficially, the problem amounted to choosing projects in the face of a highly uncertain future so that the returns (benefits) generated would be greater than their costs over time. Central to this challenge were the interrelated problems: uncertainty, and asset specificity and irreversibility.

The terms 'risk' or 'uncertainty' were used to describe the state of knowledge about the future in the absence of certainty. Andrew Stirling from 
the University of Sussex coined the term 'incertitude' and made the distinction between risk (where contingencies were known and probabilities were objectively assigned), uncertainty (either future contingencies could not all be known, or probabilities could not be objectively assigned) and ignorance (neither all contingencies nor probabilities were known). The message was that we do not know what we do not know. The problem was bigger than we thought and was generally underestimated. It led to what economists called 'bounded rationality' and the fact that humans suffered from a systemic inability to comprehend the nature, scope and scale of uncertainty (incertitude).

Aspects of incertitude that affected energy projects included:

- Capital cost: A project could lose value because an asset might cost more to create that that originally predicted and construction could take longer.

- Running costs and revenues: Running costs could be higher than anticipated and benefits could be less than anticipated. Competing technologies or energy sources could emerge rendering existing technologies obsolete.

Asset specificity and irreversibility meant that the assets were specific to an industry and could not easily be put to use in another industry. The viability of a power project was entirely dependent on the realised construction costs and not the forecasted costs, the realised value of the operating and fuel costs, and the value of its output over time given the risks. The key question was whether long-term planning would make any sense if forecasts were known to be incorrect, and the world was going to be a very different place in 15 to 20 years' time. Perhaps future strategies should be thought about differently.

At least three important perspectives shaped decision-making in the power sector: those of

- society (real economics and social welfare);

- managers of companies, concerned about business economics, cash flows and profit;

- providers of finance, concerned about financial economics, interest rates and dividend yield.

It was very important when referring to the cost of capital, risks and so forth to distinguish between private financing cost and public opportunity cost of capital. Power sector policy should, in the first instance, be concerned with the public opportunity cost in the real economy and the maximisation of social welfare. 
In terms of project appraisal, discounted cash flow analysis comprised the following steps:

- Generate unbiased estimates of cash flows.

- Determine the risk associated with different cash flows.

- Determine appropriate discount rates.

- Calculate net present value (NPV) and levelised cost (in the case of power sector).

Some key points about the discount rate (WACC and capital asset pricing model (CAPM)) were:

- The nature of ownership (public or private) did not, a priori, affect the real economy risks of a project.

- The discount rate was best determined on the basis of financing cost (corrected for risk shifting).

In other words, there should be no a priori difference between the private and public sectors in the way that uncertainty was reflected in investment appraisal. There was only one (risk adjusted) opportunity cost of capital. Furthermore, it was not only the discount rate that mattered. Cash flows with different uncertainty profiles should be discounted at their risk appropriate discount rate. Individual cost streams needed to be separated from each other into groups that had similar risk profiles and different discount rates should be used for each group within one project. In doing so, appraisal optimism, endemic in power sector decision-making, should be challenged, remembering that humans were bound by rationality and 'ignorance'.

It was necessary to understand the shortcomings of the discount cash flow (DCF) methodology in the levelised cost approach. DCF did not allow for a detailed comparison of investment options on the basis of their risk profiles, but looked at investments as a once-off opportunity and did not reflect the fact that the investments could be delayed or phased. DCF did not enable explicit comparative evaluation of the flexibility in projects to deal with uncertainty, nor did it address the problem of uncertainty and ignorance (incertitude). DCF/levelised cost comparisons that did not attempt to address these fundamental shortcomings had little real world value. It was necessary to bring in other approaches, such as real option valuation, which went some way to remedy these shortcomings, or a 'what-if' analysis, especially to show the impact of new (competing) resources or technologies emerging during the project life. 
Strategies that would improve project value in the face of uncertainty were:

- Incrementalism: 'The science of muddling through' (Lindblom, 1959; 1979), an effective response to complexity and uncertainty in the context of bounded rationality and poses a challenge to the mastery-via-understanding tradition of Western civilisation.

- Flexibility (of an investment): Allowing for trial-and-error learning (Collingridge, 1992) and enabling early adaptation to changing circumstances therefore reducing the costs of potential errors (Collingridge and James, 1991).

- Diversity (of a system): Promoting beneficial forms of innovation and growth, hedging against exposure to uncertainty and ignorance, mitigating the adverse effects of institutional 'momentum' and 'locking-in' in technological trajectories, and accommodating disparate interests associated with social choice in modern pluralistic societies (Stirling (1998: 37)).

These principles can be translated to the debate around nuclear power and to the question about the correct discount rate for nuclear by:

- Ensuring that the cash flows were adjusted for the shortcomings in the DCF approach in respect of bias, including the impact of uncertainty and ignorance and the complexity of construction and commissioning, as well as real option cost and benefits of different technologies.

- Making the point that a single number could not be used for a whole project or for different projects. Projects would have to be deconstructed in order to understand the different risk streams and set the appropriate discount rates. The correct discount rate should reflect the risk of revenues that were reliant on the price that was greater or equal to the full levelised costs over its life.

\section{Discussion: Q\&A}

Prof Tomas Kåberger: Dr Serfontein's presentation and his precision in terms of the external cost were impressive. The most important thing when comparing the interest rate is that a very low discount rate will mean that solar and wind will be very competitive and nuclear will have slightly higher costs followed by coal and gas. Another problem with nuclear is calculating the cost of waste management and decommissioning. Had you included this or had you assumed a fixed cost for decommissioning and waste management irrespective of the interest rate? 
Response, Dr Dawid Serfontein: I did not do it like that but because it is a small cost and the error is not important. I added waste management as a fixed cost of R0.03c/kWh every year. This is shown in the cash flow and is affected by the discount rate or the actual WACC and will go up if these are higher.

\section{Prof Anton Eberhard:}

1) Dr Serfontein, you referred to very long operational times of 60 years. Did you build in refurbishment expenses along the way?

2) I noticed that some of your colleagues from the NWU also published a paper on the cost of nuclear and came to opposite conclusions, namely that coal is much cheaper than nuclear. How do you explain the discrepancies?

\section{Response, Dr Dawid Serfontein:}

1) I worked in refurbishment expenses at $10 \%$ or $15 \%$ in year 35 . Things that happen late in the life of the plant do not count too much in present value. Therefore the $10 \%$ or $15 \%$ has a small effect on the levelised cost of electricity.

2) I know the study well and do not agree with their view. My colleagues used a high WACC. I wrote a document in opposition to their work but it has not yet been published. I am critical of their work. They also did not take the health costs of coal into account. The flaws that I detected in the IEP and the IRP, I also detected in their work.

Prof Philip Lloyd: Prof Eberhard insisted that the NDP should include the constraints of climate change and how to address it. At what stage do we remove the constraints given the fact it is a global problem and the global society is doing nothing about $\mathrm{CO}_{2}$ emissions? Why should South Africa take $\mathrm{CO}_{2}$ into account when the global society is doing nothing?

Response, Prof Anton Eberhard: I do not think it is true that nothing has been done in respect of mitigating climate change, although the ambitions of some have not been fulfilled. The NPC's perspective was that it was prudent to start thinking about these matters. We are one of the more vulnerable countries in terms of our reliance on carbon, and the country with among the highest dependence on coal for electricity generation in the world. There are some concerns about the potential exposure of South African trade in terms of border tariffs in the future linked to the extent to which our exports rely on dirty energy. There is a more positive way to think about this. Look at how the electricity plan 
has been transformed since a carbon cap has been imposed on the modelling. This has forced us to look for alternatives. Previously, all plans were centred on coal and so coal power stations were built. We have now considered renewables and through embarking on an interesting IPP programme in renewable energy, we have been able to see what the market can do and what innovation can take place. Three years ago one could not have predicted that wind prices would be below $70 \mathrm{c} / \mathrm{kWh}$. PV prices dropped $68 \%$ between round 1 and round 3 , and wind prices by $42 \%$ between the rounds. Through adopting a kind of self-imposed carbon cap and deciding to go for a more diversified energy mix, South Africa has been exposed to interesting innovation and experience, which can only add to our energy security going forward.

Unknown person: Dr Serfontein mentioned that nuclear was not good for peak load. It is wrong to maintain that nuclear cannot handle peak load. In France, about $80 \%$ of the country is run on nuclear and it handles peak load very well.

Response, Dr Dawid Serfontein: Nuclear plants can do peak following but the load factor decreases; this is a problem because a lower load factor means a lower profit. In France, the main cost of nuclear plants is the capital cost. If the load factor goes down the cost of electricity goes up. Although load following by a nuclear plant is possible, it negatively affects operations and profit. A certain chemical (Xenon-135) is released and increases inside a nuclear reactor if power is decreased, poisoning the reactor and causing operational problems.

Prof Harald Winkler: I agree with Dr Serfontein that external costs should be included. The ERC researchers engaged with National Treasury and the response was that $11.3 \%$ was intended as real discount rate and not a nominal one, reflecting not only the cost of capital, but also an opportunity cost to South Africa. With regard to your comments in relation to the LCOE and the long lifetime of nuclear, it should be noted that our modelling calculates the LCOE of different technologies based on their projected lifetimes and not the modelling period.

Response, Dr Dawid Serfontein: I have read that the discount rate should also be decreased later in life. After 20 years, the plant is paid off. If there are two plants at the same cost and one works for only 30 years and the other works for up to 60 years, the high discount rate model will indicate that there is no benefit for the plant with the longer 
life. However, there is obviously a benefit because it works longer. If a plant works for double the time it also mitigates double the amount of $\mathrm{CO}_{2}$ emissions. Thus, this is a real benefit, which is hidden by the unrealistically high discount rate.

Dr Kelvin Kemm: Long-term planning does make sense. We are in a position in history where we are able to do this. We have certain reaches into the future that we did not have in the past. Instead of projecting into the distant future we should look at what we have got and what we can do, and use this for long-term planning.

Dr Grové Steyn: I realise that I am challenging a paradigm. Unfortunately it is our history that challenges this paradigm that we hold on to. If we want to stop repeating history, which we are currently bound to do, we need to take a long hard look at what we are doing. My PhD research was the basis of a paper I wrote that foresaw Eskom's current situation by looking at what had happened earlier on, in respect of Eskom's planning in the 1970s and 1980s and what happened in the UK with the Central Electricity Generating Board around technology issues and forecasting uncertainty and so forth. The question is what are the lessons we can learn? Things go very wrong in almost every infrastructure sector. Do we continue doing the same things and expecting different outcomes? This will not help. We need to find new ways to approach the issue. One of the lessons is that there is a price to uncertainty and risk. The greater the uncertainty when it moves to the realms of ignorance, the more chance there is of getting long-term planning wrong. Long-term planning cannot be done. It does not work. We need sensible strategies for the long term as opposed to a single long-term plan. This is why the IRP update is very different from the original IRP 2010 as it is based on scenarios and not a single long-term plan. This is a step in the right direction as we are beginning to recognise our limits as humans. This does not mean that technology is not wonderful. Technology and the economy are so wonderful that we cannot predict them.

Prof Rob Adam: With regard to the NPC's view on importing power from outside South Africa, the generally received view is that you should not get more than your reserve margin from outside your own country. The local construction industry is backing off from renewables in South Africa and looking north because the tariff that you can get in other African countries is better than what the tariff will be here. A different 
kind of company will bid for South African projects. They will probably fund projects off the balance sheet of utilities and local companies will not be able to compete.

Response, Prof Anton Eberhard: Currently South Africa has very low exposure to imports in electricity. There are some very good projects in the region (apart from the Grand Inga Dam project in the Democratic Republic of the Congo (DRC)) that are very attractive in terms of cost and supply security. There are diverse sources of gas. In five to seven years, knowledge of our offshore and shale gas resources will be much better. There are a range of indigenous sources that could help diversify our sources and increase supply security. In respect of renewables, the trend that you described is correct. The returns that companies are earning on round 3 versus round 1 are much lower and it has become much more competitive. It is interesting that round 3 had a record number of bids at 93, only 17 of which were awarded. There will probably still be competition in rounds 4 and 5 , which will be good for consumers.

Dr Kelvin Kemm: I take issue with the comment that more competitive wind prices are good for consumers. The case for wind was generated in the first place for political reasons because of a belief in $\mathrm{CO}_{2}$ causing global warming, which is turning out not to be the case. Wind is not practical and is still very expensive compared to coal, nuclear and other technologies. We organise contracts in South Africa, as in many places in the world, where people who put in wind power are guaranteed long-term money from the government at the taxpayers' expense. Wind is not an energy solution but a political reaction to an international political issue.

Response, Prof Anton Eberhard: It was hoped that ideological positions against particular technology choices would not be taken at this symposium. It was important to have an evidence-based discussion around the options including nuclear. Let us be careful about what has been said about wind. Bids for wind in Brazil are even more competitive than in South Africa. Wind energy is not being subsidised in Brazil or South Africa. Furthermore, Eskom is getting data on actual output of wind and PV from the projects that have connected. 
It is very interesting that at different parts of the load curve, wind is displacing more expensive energy sources. We must look at the economic value that the technology provides, and while it is not a panacea, it is a very useful potential contributor to the energy mix going forward.

Mr Andrew Kenny: When you are looking at investing in a power station, one thing that makes it a safer investment is that the product (electricity) never changes. This means that one massive risk to industry (the risk that there will not be a market for its product) does not exist.

Response, Dr Grové Steyn: There is risk for a particular project based on a particular cost profile. First there is the demand side. There might not be demand for the product or the demand forecast might be wrong. Now that the prices reflect the true costs more accurately there is a response from the market. Energy efficiency, demand-side management and other factors affect the demand for electricity. Competitors may be able to sell electricity at a lower price and cost than you in ten years' time. If the project can be displaced by cheaper technology in the future then this is a risk that has to be considered.

Prof Rob Adam concluded that progress had been made in shaping some of the issues that decision-makers would be faced with from the economic and financial perspective in making energy choices in terms of the final, updated IRP. 


\section{SESSION TWO:}

\section{OUR NUCLEAR FUTURE IN THE CONTEXT OF INTERNATIONAL DEVELOPMENTS}

(CHAIR: PROF ANTON EBERHARD, UNIVERSITY OF CAPE TOWN)

\section{International Trends in Nuclear Power Investment and Costs \\ (Prof Tomas Kåberger, Chalmers University, Sweden)}

"Plans are useless, planning is everything" (words attributed to General, and later US President, Eisenhower).

The process of trying to understand what may happen in the future and the ability to act quickly when conditions change are extremely important. In the energy policy debate in Europe, especially in Sweden, the most important constructive step taken as a result of work done by the Energy Commission and energy researchers was to unbundle the electricity grid from the production and trade in electricity. Private investors had to decide on the most profitable alternatives. The attitude of researchers and others who tried to assess costs was very different when the decision-makers were responsible for the investments they made and more constructive than when those experts who made claims about costs were passing the responsibility for the actual investment to others. This applied to very large investments, as well as any small-scale investments in renewables. This change had been extremely constructive for the actual efficiency of the electricity system development, as well as for the debate, and had improved security of supply because those who promised to deliver electricity were obliged to do so or pay.

The construction of nuclear reactors during the previous century peaked in the 1980s. The global nuclear industry declined in the 1990s and many of the vendors left the industry during this period. Around the turn of the century there was hope for a revival of nuclear. High oil prices, 
climate change concerns, local air pollution and increased fears of dependence on oil supplies from a few, mainly Middle Eastern countries, added to the need for other sources of energy and electricity in particular. For many years there were only a few reactor construction projects but statistics from the International Atomic Energy Agency (IAEA) showed that the number of ongoing reactor construction projects had increased in the last decade. The increase was largely due to a number of reactor projects in China and a few other countries and many of these projects had been ongoing for a very long time. However, the number of operating reactors had decreased to the lowest level in almost 20 years.

One of the main reasons why the nuclear industry had problems competing was that the cost of nuclear reactors in the world had often been higher than anticipated when the decisions were made. The fact that the real costs were higher than anticipated was an important factor for investors. Learning curves for nuclear power, using the French and the US nuclear reactor projects as a source of data, showed that costs increased as experience was gained, partly due to a greater awareness of risks resulting in more precautions and cumulative complexity of the plants.

A project that had attracted much attention in Europe was the Olkiluoto 3 plant, built in Finland with Areva supplying the nuclear components and Siemens supplying the electricity generation components. The project had been delayed and the owner of the plant had recently reported that Areva could no longer provide a plan for completion.

Making cost projections was often described as an art and not a science. The Finnish plant was an example of the difficulties of seeing the real costs. The contract price was $€ 3.2$ billion and it was supposed to be a turnkey contract with a time schedule. However, costs have soared. Areva had set aside $€ 3.9$ billion as anticipated losses by 2014 . In addition, there were provisions for contract completion and Areva had sued the customer for the delays and extra costs of the project to the amount of $€ 2.7$ billion. In turn, the customer had claimed $€ 1.8$ billion from Areva. The total cost had therefore reached $€ 12.4$ billion. The addition of interest during construction would bring the total cost to $€ 16$ billion, which at an interest rate of $8 \%$ would result in electricity costs of about $€ 100 / M W h$ from this plant. Although this was not a typical case, it could discourage private investors from investing in complex projects 
such as nuclear, necessitating significant state guarantees and state subsidies.

An insignificant number of new plants had been taken into operation during this century. Japan's maximum nuclear generation was in 1998 when the official policy of increasing nuclear power in Japan failed, although it did not collapse until the Fukushima accident in 2011. In Sweden, nuclear power generation peaked in 2004, in the rest of the world it peaked in 2006 and in the US it peaked in 2010. This would not have occurred if nuclear power and fossil fuels had been the only alternative sources of electricity. The use of renewables had increased dramatically.

Wind power was the most significant increasing contributor. It had not been predicted in the last century that China would be the highest producer of wind power in the world. Wind power had overtaken nuclear power production in China in recent years. That country had completed one wind power plant every hour throughout the year for the last five years and had built the most nuclear plants. Cost figures published in 2013 in the US indicated that wind power plants built in 2012 had cost US\$ 40/MWh, a cost that was competitive with any other source of electricity. In Australia and India, wind power was cost competitive with coal without subsidies. The unreliability factor of wind generation had shown to be manageable. More than one third of Denmark's annual electricity was from wind power. That country had found solutions to all the challenges of varying wind power and its parliament had taken a decision to increase wind power to $50 \%$ of the annual energy generation by 2050. Denmark had experienced oversupply that resulted in negative electricity prices.

Solar had also shown substantial growth. Germany built the most solar power plants, which were paid for by German households. Ten years ago, the idea was to subsidise solar in order to bring down costs and make solar competitive globally. It was calculated that if all Organisation for Economic Co-operation and Development (OECD) electricity customers shared that cost it would be approximately R0.01 / kWh, but solar power was much more expensive because the full cost was carried by German households. Recently, costs had come down and in the last year many countries were investing in and installing new solar power plants. The German transformation had led to an increase in renewables by about 110 TWh since the turn of the century and nuclear 
had decreased by about 75 TWh, and renewables had largely been used to increase exports and reduce the share of fossil fuels in the electricity supply.

China's recent five-year plan increased targets for renewables, particularly targets for solar, which were to increase by $27000 \%$ by 2020. Although some economists did not trust environmentalists or scientists, the Financial Times published an article citing reports stating that an unsubsidised solar revolution had begun and this drew the interest of many financiers to solar energy technology, which led to even lower costs of solar power as financing of PV installation became easier.

The traditional power industry faced numerous problems. Nuclear waste costs were not negligible. Although good planning ought to keep costs under control, this had failed in Britain, one of the pioneering nuclear nations. If the $£ 70$ billion spent on managing a single nuclear waste site had been invested in wind power plants, between 125 and 150 TWh would be produced every year, more than all the British nuclear power plants had ever managed to deliver in a year. Although the power industry may not have changed for 100 years, it was currently undergoing dramatic change. An article in the Wall Street Journal reported that US companies were unplugging from the grid. This was a clear indication that grid-connected power was an unsafe investment. Companies in the US found it cheaper and more reliable to provide their own electricity generation with some storage. In Europe some large power companies have had to write-off assets. European electricity providers faced an existential threat from the competition from new renewables, which had become cheap and would become cheaper and more competitive in the coming years. Nuclear investments were not very successful and the risks were increasing, while the cost of renewables was decreasing rapidly. This trend would continue into the foreseeable future.

\section{The Case for Nuclear Power}

(Prof Philip Lloyd, Energy Institute, Cape Peninsula University of Technology (CPUT))

There had been all manner of attempts to predict future demand and most predictions had made the mistake of assuming compound growth. Many developing societies showed log-linear growth with time 
but South Africa's growth was linear. World Bank data showed how power had grown between 1971 and 2010 in several societies. South Africa followed linear growth similar to that of countries such as Belgium and Columbia, and surprisingly, followed the almost identical production of power to Australia. South Africa had been faced with a supply constraint since 2007, as predicted by the DoE, and many large users had fallen away while others had come under threat.

The last few years should be viewed as an aberration. It was essential to return to a linear view of the future where consumption would be $4.0 \pm 0.5^{*} 10^{11} \mathrm{kWh}$ by 2035 and $4.9 \pm 11^{*} 10^{11} \mathrm{kWh}$ by 2050 , comparable with the IRP update.

How the country might meet its future demand has been the subject of much thought in recent years. In March 2011, Cabinet agreed to a final version of policy-adjusted IRP 2010, which had been revised to reflect some policy constraints. In November 2013, the DoE published an update of IRP 2010, which stressed greater flexibility in energy planning and dismissed the multi-criteria decision model. The latest idea of a decision tree was a much better way to address the problem.

The IRP update focused strongly on providing the generating capacity to meet the peak demand. However, the ability to generate sufficient power to meet daily needs was as important as meeting peak demand. The IRP 2010 revised data were reassessed on a TWh per annum basis making certain assumptions, namely:

- Load factors of $85 \%$ for coal, $50 \%$ for combined cycle gas turbines (CCGT) and imported hydro, 60\% for local hydro, 92\% for nuclear, $30 \%$ for wind and 'other' sources of power, $40 \%$ for CSP, $20 \%$ for PV, and $5 \%$ for OCGT and pumped storage.

- Baseload was $70 \%$ of coal, $100 \%$ of nuclear and hydro.

- Mid-merit was $30 \%$ of coal, $100 \%$ of CCGT and 'other' sources of power.

- Peaking was $100 \%$ of OCGT and pumped storage and $40 \%$ of CSP.

- Variable was $100 \%$ of PV and wind and $60 \%$ of CSP.

For illustration purposes the 'SO Moderate' scenario from the IRP update was used to plot the base, mid-merit, peaking and variable power to be expected, and the margin to be expected was calculated in order to assess how well the supply would meet the demand expected for the specific scenario in terms of TWh per annum. The margins were 
erratic and plunged after 2025. All the scenarios were tested and produced the same results. Under the 'Weathering the Storm' scenario, the baseload decreased after 2025 because it reached the $\mathrm{CO}_{2}$ limit that had been set. This scenario provided baseload only in coal.

The IRP update revision had problems because the focus on meeting the peak demand overlooked the need to meet the annual demand. Planning should take the annual demand as well as the peak demand into account. As presently planned, the country would move rapidly into another supply crisis from about 2020 onwards. The source of the supply crisis was the lack of growth in baseload supply in particular. In some of the IRP scenarios, baseload actually fell from 2020 onwards. The problem was accentuated by the planned growth in variable power sources. International experience showed that to accommodate the variability, it was essential to increase the reserve margin once variable exceeded $\sim 5 \%$ of total supply coming from the variable power sources. Spinning reserve was necessary for when the sun did not shine or the wind did not blow. According to nearly all the scenarios, $5 \%$ would be exceeded in $\sim 2025$. The analysis of the IRP 2010 showed that this lack of baseload had arisen from the desire to avoid $\mathrm{CO}_{2}$ emissions. The 'preferred' baseload technology as selected by the IRP update was still coal, with its inevitable carbon footprint. The obvious answer was to look to another technology such as nuclear, but this was actively avoided in the IRP update, which assumed a very high capital cost for nuclear plants, in the area of US $\$ 5800 / \mathrm{kW}$ installed. In addition, the 'sensitivity analysis' increased the cost of nuclear even further to US\$ $7000 / \mathrm{kW}$ installed. The IRP update was supported by a good series of technical reports from the Electric Power Research Institute (EPRI) in the US. The Institute's cost estimates for all technologies were confirmed by the bidding as being higher than the average Eskom cost, but its estimate (in the area of US\$3 200/kWh) for nuclear was not taken seriously. There was a clear indication of active avoidance of the consideration of nuclear in the IRP update.

One of the prime drivers for nuclear was the desire for lower carbon emissions. South Africa had a policy to plateau emissions by 2025 and to decline thereafter. The DoE had stipulated that the energy industry may emit 235 million tons of $\mathrm{CO}_{2}$ a year from 2025 onwards and this would drive the energy plan because there were only ten years left to reach that target, which was non-negotiable. Therefore concrete steps would have to be taken to achieve the set target and a technology 
would have to be found that met the requirement. Globally, generating electricity and emitting $\mathrm{CO}_{2}$ were linked and emissions could not be cut unless the technology of generation was changed. Only nuclear and gas would provide the required baseload. All the renewable energies cost more than Eskom's average cost of power. The EPRI cost estimates were reasonable and credible. There was little option but to incorporate a nuclear fleet, unless substantial amounts of gas were found soon. Nuclear would keep the wheels of industry turning and keep electricity affordable. Koeberg was already Eskom's lowest cost source. Nuclear would enable the country to meet some of the $\mathrm{CO}_{2}$ targets. Germany and Japan had to scrap their targets because they chose to close their nuclear fleet. Without a doubt, nuclear power was an essential component of South Africa's energy future.

\section{Discussion: Q\&A}

Dr Dawid Serfontein: Prof Kåberger said that nuclear is not profitable in Europe. Is this because there are hidden subsidies and hidden costs from the renewables that are placed as a burden on the other generating technologies? When the sun shines and the wind blows, nuclear is expected to act as spinning reserve, which is a system cost that renewables place on nuclear. The bill should be sent to renewables but it is charged to the nuclear plant. The same applies to rooftop PV. In South Africa we produce power for R0.50 but it is sold for R1.50. The additional $R 1$ is for distribution costs and taxes. Rooftop PV is sold at R1.50 to Eskom and this means that the hidden cost is that distribution costs and taxes are not paid.

Response, Prof Tomas Kåberger: There are some differences in the various European countries. In Britain, there is a special contract for a new nuclear reactor. Even those who believe that nuclear power is expensive accept that this power plant will be profitable because at $£ 92 / \mathrm{MWh}$ it should be capable of 'burning money'. In most European countries we have an electricity market. Any producer offers electricity to the market and consumers bid for prices to buy. There is a price settlement at least every hour. The result is that a wind power plant can produce when the wind is blowing and will have to bid with many other wind power owners. The price will drop and less profit is made, with the exception of countries like Germany where there are feed-in tariffs, which make the market less efficient. The power plants that used to be the lowest marginal costs plants, coal and nuclear, can no longer 
operate constantly because the bids from solar and wind will undercut their bids. Coal certainly does reduce the power in Germany at the moment. In managing electricity systems we see that the old concept of peak load and baseload has changed its meaning because the lowest marginal costs are no longer coal and nuclear but solar and wind. When they are available they will produce and deliver whilst coal and nuclear will come next, which in the longer term will mean that these power plants will not be able to operate throughout the year. On the other hand, power plants that are more flexible will become more valuable and profitable while coal and nuclear will be less profitable. This is the way the market is working and this is why there are large losses in the European power industry. I do not think it can be said that costs are being pushed over to coal and nuclear, but in Germany there are significant advantages from legislated fixed tariffs.

Prof Rob Adam: How do the graphs (in Prof Kåberger's presentation) look when the $2000 \mathrm{MW}$ of nuclear that China is aiming for by 2030, is installed. I am a little surprised that you always counterpose nuclear with renewables. In my view you need to have both. Nuclear, coal and gas are needed for baseload and unless the grid interconnectivity is profound, it will never be possible to go to $100 \%$ renewables. Categories are being confused in order to make another point.

Response, Prof Tomas Kåberger: China's last five-year plan was not clear about nuclear ambitions and there have been significant uncertainties in Chinese policy. Although they are building 28 nuclear reactors, this is less than they had planned originally. In China, the competition between renewables and nuclear is totally insignificant. In Europe, it is different because renewables provide a large share and prices are falling because of the supply of electricity with very low marginal cost. An investor will see that the opportunity to build 'high investment cost low operating cost stable production' units is not necessarily available. There is the challenge that if a new coal-fired power station or nuclear power station is built it will not be able to operate for $80 \%$ to $90 \%$ of the year, and this makes the economics much worse. Baseload is not the same thing as it was 20 years ago. There are not the same 'low marginal cost high capital cost' coal and nuclear plants as before. Now there are renewables that have different characteristics.

Mr Andrew Kenny: When Prof Kåberger refers to nuclear projects, he refers only to projects that are unsuccessful and are all one kind of 
reactor. There are reactors that are built cheaply, simply and on time all around the world. Modern nuclear plants are becoming simpler, not more complex. Production costs for nuclear are the cheapest of all technologies. In Denmark, one third of electricity produced is wind and Denmark has the highest electricity prices in Europe. France, which is $80 \%$ nuclear, has one of the lowest electricity prices in Europe. In terms of bidding, in England, nuclear comes in at zero. The massive subsidy is this: In Britain and Germany, regardless of the demand, when the wind is blowing the customer is compelled to buy wind power.

Response, Prof Kåberger: I agree that the European nuclear experiences are bad and there may be better experiences in other parts of the world. It is not easy to get trustworthy cost data from China, for example. I would like to see good performance data from real completed reactors. The most important thing is to have an open market where those who argue and take a stand are also those who pay. It is not really true that the subsidy is that grid companies in Germany are obliged to accept the electricity, because on the market the renewables will always offer their production at very low prices, close to zero. Even if there was not an obligation to receive the electricity they would offer their electricity. The feed-in tariff is a problem as that distorts the market. In Europe there is no feed-in tariff. The price paid for wind power is set by the renewables spot market and the plus certificate value. At least electricity generation is operated depending on the spot market price, which is a lot better than the German situation.

\section{Dr Kelvin Kemm:}

1) We need to recognise that what is happening in Europe as in other places in the world is that there has been massive political interference in the electricity prices. There is no free market operating in this area. The reason why electricity prices go down to zero is that nobody wants it. The point with electricity is that it must be continuously and reliably available otherwise industry cannot run. Denmark's solution to the variation, resulting from wind power, is a cost settlement every hour. South Africa is the same size as the whole of Europe and cost settlements between Cape Town and Johannesburg are not practical. We cannot look to Europe for our solutions and we must provide electricity at any time of the day or night to the people and industry in this country. 
2) Prof Kåberger quoted figures in TWh. A distinction must be made between TWh, TW, GW or MW. Prices cannot be based on the total amount of nuclear or solar in a year. We need to be realistic about what we want. Renewables are intermittent by nature and will not provide continuous baseload. Political interference to put in renewables to supposedly save the planet from $\mathrm{CO}_{2}$ has placed the energy system in a serious situation.

\section{Response, Prof Tomas Kåberger:}

1) I have no problem with the distinction between TWh and GW, as one cannot describe every point on earth in both energy and power terms in a graph. A selection must be picked and if you pick GW alone, renewables will look much better than in reality and if TWh are used then the availability at different points in time is missed.

2) It is true that the electricity market in Denmark is smaller than South Africa and that Denmark is interconnected. South Africa is nearly the same size as Europe and Europe's electricity market is interconnected. We do trade in electricity every hour throughout the whole continent. It is not something that is isolated. It is possible to have a power market over many countries, with constraints in transmission capacity within the whole market. This is not a problem. The important thing with a functioning power market is that it actually improves the reliability. The supply security is higher in Europe now than what it was when there were monopolies. One important mechanism is that if you fail to deliver what you promised in the power market, you have to pay, unlike in national monopolies. This is a problem in Eskom. Reliability has improved in Europe and we do handle the fact that wind power is not perfectly predictable. Wind power owners who fail to honour the delivery commitments made have to pay. The system works surprisingly well and we are not worried about supply.

Dr Grové Steyn: The examples used by Prof Kåberger illustrate my explanation of risk and uncertainty when planning new power projects, particularly the risk of being displaced when a new technology displaces the cost. Is this a correct understanding? Are we finding that the older coal and some nuclear plants are essentially being displaced by cheaper renewable power through competition? Are we talking about a complete paradigm shift emerging in the power sector with the role of demand side and an intelligent grid, perhaps on par with what hap- 
pened in telecommunications 20 years ago? Is the way we are thinking about baseload, mid-merit and peaking no longer valid?

Response, Prof Tomas Kåberger: Yes, there are dramatic changes in the power sector. I try to avoid referring to baseload and intelligent grids. We can hope for information technologies that will help consumers utilise variations in electricity prices to save money by controlling their consumption. This is slowly beginning to happen. The risk spectrum for investors in this sector is very large at present and is not only a matter of new technologies changing the competitiveness in the electricity grid. People might start disconnecting from the grid. This would be a very dramatic shift.

Dr Grové Steyn: We are talking about $9600 \mathrm{MW}$ of nuclear power, and finance of about R1 trillion. How does Prof Lloyd foresee this happening in South Africa given that the Department of Public Enterprises is in negotiation with National Treasury for a further bailout of Eskom?

Response, Prof Philip Lloyd: It does not matter whether the $9600 \mathrm{MW}$ comes from renewables, coal or other technologies, it will still cost a great deal. The important question is about the timing of the installation of the fleet. This is not apparent. It is sensible that it is installed as a fleet because the learning curves will come out of building multiple reactors. In the IRP update, there is a very steep curve on improvement for CSP that is not revealed in the cost curves we have seen so far coming out of the bids. The DoE has completely underestimated the rate at which building a fleet of nuclear reactors would improve the learning curve.

\section{Facilitated Discussion on South Africa's Nuclear Energy Future}

\section{Costs of nuclear (specific investment costs and what these might be in the South African context)}

Dr Kelvin Kemm: We can avoid the errors made elsewhere and we have to look at it from a South African perspective. What has happened at Medupi and Kusile power stations, some of the biggest power plants in the world, was that we did not take into account the gap in time and the loss of skills since building the previous power stations years ago. Some relearning had to be done to build these massive new power plants. These learnt skills should be taken into the nuclear construction 
because the project management was a major factor in the costs. With regard to the overall costs, it has been said that there is a target of $50 \%$ local content on the first nuclear plant. If there is a $50 \%$ local content, half the expenditure is spent in this country and will cause domestic growth. Infrastructure growth will mean increased electricity consumption. We should plan for this.

Prof Rob Adam: We have heard the eloquent and professional presentations during this symposium. This almost points to an ASSAf team that would move forward and try to make a consensus contribution to the field. We can begin by outlining the issues during this discussion. If the first two units cost R150 billion, $50 \%$ is R75 billion. The projects would have to be bonded at a level of about R30 billion. The market capitalisation of the entire South African construction industry is about R50 billion. There is no way that shareholders would permit this. If government wants to go ahead with those levels of localisation they would have to address this issue. There needs to be an understanding between government and industry as to what the deal is before we can proceed otherwise there can be an expectation and a threshold given to vendors, which is actually unattainable.

Dr Dawid Serfontein: I would like to explain some of the results I have on why the costs are so high in the West and this will explain why it is possible to bring the overnight costs down. The Three-Mile Island accident, followed a few years later by the Chernobyl nuclear disaster caught the world completely by surprise. Suddenly, in the midst of construction of new plants, regulations became much more stringent. This pushed up prices from about US $\$ 1500 / \mathrm{kW}$ before the accidents to about US $\$ 6000 / \mathrm{kW}$ a few years later and so the industry in the US collapsed. More recently, Olkiluoto was quoted for US $\$ 3500 / \mathrm{kW}$ but the costs increased to about US $\$ 7000 / \mathrm{kW}$. If US $\$ 7000 / \mathrm{kW}$ had been quoted from the start, it would have been an amazing achievement because it means that there had not been a substantial cost increase since the last plant built in the US to the first built in Europe, which is a next generation reactor. The same team that did the building in Europe is now working in China. They were over budget and behind schedule in Europe but they are below budget and ahead of schedule in China.

Prof Anton Eberhard: Rosatom in Hungary is one of the most recent contracts that have been signed. The specific investment costs (unsure whether an overnight cost or a fully wrapped cost) is about US $\$ 7030$ per installed kW. 
Dr Dawid Serfontein: This is a similar case to the Hinkley Point plant. Either the plant is sold and a selling price is asked, or there is a contract using an overnight price as one of the determinants to work out what the contracted selling price of the power will be. The overnight cost should be viewed in the context of the whole contract. In the case of Rosatom a high capital cost and very low interest rate were used. In the end the production cost of the electricity is low, and that is all that matters. This means that one should not look at the capital costs, but at the full contracted power price that is being offered. In addition to Hinkley Point, the British also awarded contracted selling prices for wind and solar, and nuclear came out a bit cheaper than all the rest.

Prof Anton Eberhard: Capital costs are relevant as they ultimately inform what the contract price would be. The issue is whether we are getting the accurate contract prices.

Dr Grové Steyn: I want to make a comparative point on the question of the capital cost of these mega projects. If we were now at the point where decisions were being made about Medupi and Kusile, we would do the same thing and get the international comparative prices and try to find a benchmark of what it would cost to build the power stations. I am making the point that we cannot be building the most expensive coal-fired plants in the world. For the same reason that we have problems with those two plants, we are going to build the most expensive nuclear plants in the world if we go the route of a mega, complex project. This is unfortunately the history of all our power projects. On paper the economies of scale and the other details look good but in reality there is a huge premium on projects that allow incrementalism, flexibility, delays and so forth. In a competitive market, it is those projects that always have problems. If the problem of uncertainty is ignored then you will think that the larger-scale mega projects will be cheaper but in reality we cannot forecast the future and the large projects will often go wrong for reasons of complexity, construction costs and incorrect demand forecasts. The smaller, more modest and more incremental projects almost inevitably and in the real world end up a lot cheaper. This is the experience in Europe, Britain and the US.

Prof Anton Eberhard: It is clear that there are divergent views and a range of data around costs for nuclear. The debate has helped clarify the kind of numbers we are talking about, whether specific investment 
costs (overnight cost), or all in-costs. We need to be more precise in our debate. We are also clear that the range of prices from Europe is different from those in the East and the implications of those costs for our own environment need to be interrogated further. We have also heard about potential risks of managing the large projects over time. One of the obvious lessons is that the way in which these contracts are structured will be absolutely critical. The risks must be wrapped and the vendor, rather than the consumer, should bear construction and cost risks.

\section{Discount rates and the cost of capital}

Prof Anton Eberhard: Discount rates are employed by economic modellers to compare different technologies. Good sets of arguments have been heard around how they should be used from a risk-adjusted perspective. We understand clearly that a lower discount rate will give a different answer in respect of the favourability of nuclear. We have also heard that discount rates are helpful in the initial screening of different technologies but ultimately what counts is what is being paid for the actual cost of capital. This is an interesting debate in the South African context where we understand that we are in a fiscally and debt-constrained environment and it was unlikely that National Treasury would invest directly in a nuclear programme. The issue was whether Eskom would be able to raise debt on its balance sheet. Those who have considered this matter are of the view that it would be very unlikely in the next few years. The focus now is on what kind of funding vendors would bring to a potential nuclear programme.

Mr Andrew Kenny: The cost of capital is critical. Construction delays and regulation delays will kill projects. Dr Steyn mentioned the reason why nuclear would not suffer from the same problems as Kusile and Medupi. Medupi and Kusile are both once-offs and one of a kind. Unit costs, the cost of capital and construction times will come down if a fleet of nuclear plants is built.

Prof Harald Winkler: We tend to use the discount rate in the context of national energy modelling and we do, as a matter of course, run sensitivities. I am really interested in the methodology presented by $\mathrm{Dr}$ Steyn, the focus on cash flow and integrating technology specific risks. Dr Serfontein's robust critique of almost every other study including that of the ERC, is appreciated. It would be very interesting from the ERC's 
point of view to make a process point and do further analytical work on how and when a discount rate applies and for what purpose from the public, private or any other perspective. It would be valuable to unpack this and all the acronyms that have been used.

Prof Anton Eberhard: The issue of capital cost and the actual cost of financing all ultimately translate into a contract price. If the model that would be followed for our nuclear will be a vendor offering a package, which is ring-fenced, turnkey, where risks that are wrapped, then the key issue would be the contract price. The issue of transparency around the contract will arise and whether it will be a fixed index price over time. This can be compared to other alternatives.

\section{Planning}

Prof Anton Eberhard: Planning has framed our discussions. We started by looking at the IRP and its update and had inputs from Dr Steyn on the issues of incertitude, uncertainty and how more recent and modern approaches take account of flexibility in investment decisions. One of the advances in the IRP update is that it has started taking this approach where there are a number of scenarios instead of one fixed plan. How could our planning frameworks be improved and how would they assist investment decisions for nuclear?

Mr Tony Surridge: With regard to demand and supply, the large energy user will not invest until they have certainty of supply. Unless there is commitment to a plan, they will not invest. Supply and demand seem to be a catch 22. The decrease in demand could be due to the shortage of supply.

Prof Anton Eberhard: Although the IRP update has assumed lower electricity demand it has done this only for the historical period. It says that where we are today is lower than where we thought we would be and uses this as the starting point. Aggressive demand growth scenarios have been adopted, which are linked to the NDP growth aspirations. The IRP update does plan for future growth. 
Prof Tomas Kåberger: The wrong summation is one that is traced in the European and American situation because you often have the large electricity consumers also being investors in production or actors who sign offtake agreements with the investors making financing much easier; a little uncertain prices where hedging and off-take agreements become more important for investors. The relationship between the producers and the consumers, already at the investment stage, has become stronger with the competitive electricity market.

Prof Harald Winkler: Even if all the evidence that climate change is 'unequivocal' is ignored, you cannot both deny that climate change is not real and argue that lower $\mathrm{CO}_{2}$ is an advantage for nuclear power. This is inconsistent. The general approach that applies to all energy planning whether or not nuclear is to move from a single long-term plan to a flexible plan that does have the long term in mind. This is an approach to decision-making under uncertainty (emphasised by $\mathrm{Dr}$ Steyn) and investigating both high and low costs and different discount rates. This is the kind of information that we need to apply to nuclear, as well as other technologies.

Prof Philip Lloyd: Lessons can be learnt from how the Northern European market (not the German market) has had to adapt and one can come up with an efficient model that attracts diversity into the supply system and allows various sources of energy to be accommodated. South Africa is missing an independent efficient market operator and until there is change we are unlikely to make progress towards the modern system that has been found to be successful in much of Europe. In the debate about costs, it has been forgotten that the cost of unserved energy exceeds the cost of energy many, many fold. This means that whatever the planning, always aim for a little bit more than is needed. Never underestimate the demand. Recently we have faced consistent underestimation of the need.

Prof Anton Eberhard: Prof Lloyd made these two excellent points:

- Although we have been focusing on planning and investment decisions around particular technologies, this should take place within a broader electricity market structure. Achieving this would help make the planning, procurement and contracting processes much more sustainable.

- The lack of electricity over the last few years has been a very serious constraint on economic growth. 
There is recognition of the importance of this debate and of making appropriate decisions around the electricity future of South Africa so that the economy can grow and the various goals and visions of the NDP can be achieved.

\section{Recap and Closure}

\section{(Prof Daya Reddy, ASSAf)}

The presentations have helped to set out the broad framework within which the nuclear energy of this country functions. A recurring theme of the symposium was that of the complexity of the terrain, particularly in the context of the shift in the IRP to the recognition of the need for a long-term strategy, rather than firm decisions on the future. Dr Steyn's presentation on uncertainty analysis and all that it implied had consolidated this section of the proceedings.

The discussion about cost, particularly in relation to the amount of time spent revisiting and reinforcing some of the complexities around cost of capital, discount rates and construction times has been most appropriate. Dr Serfontein's presentation was experienced by some participants as counter-intuitive and a very helpful contribution to the debate.

Prof Kåberger's presentation provided an opportunity to step back from the South African debate on nuclear and gain insight into an international perspective. The message of his presentation was that of the coming of age of renewables, the extent to which renewable energy was a major component of the energy mix in many countries, particularly in Europe and China. China was adopting renewables aggressively and at the same time it was in the process of building 28 new nuclear reactors. Much could be learnt from practices and experiences of nuclear all over the world. South Africa should be willing to learn these lessons.

ASSAf's view that this should be a scholarly debate, one that was reinforced and underpinned by evidence, had been upheld with very few exceptions during the symposium. The presentations and the Q\&A sessions were of a high quality and provided the platform to understand some of the key issues, the analyses and their consequences and implications. 
The outcomes of this symposium would include the production of a proceedings report and engagement with government to convey the usefulness of the symposium and ASSAf's wish to interact with a view to adding value to the energy planning process, given what had emerged from the meeting. In addition, ASSAf would consider undertaking a consensus study on the topic of this symposium.

Prof Reddy thanked Prof Eberhard for his role in initiating the sequence of events that had led to the symposium and for chairing a session, Prof Diab and the ASSAf Secretariat for setting up the programme and organising the event, and Prof Adam for chairing the first session and for his substantial input into the organisation of the symposium. Prof Reddy commended the presenters, the panellists and the participants on the valuable quality of the presentations and the debate during the proceedings. 


\section{References}

- Collingridge, D., 1992, The management of scale: big organisations, big technologies, big mistakes, Routledge, London and New York.

- Collingridge, D. and James, P., 1991, Energy policy in a rapidly changing market, Long Range Planning, 24, 101-107.

- Lindblom, C.E., 1959, The science of 'muddling through', Public Administration Review, 19, 78-88.

- Lindblom, C.E., 1979, Still muddling: not yet through, Public Administration Review, 39, 517-526.

- Schneider, M., Froggatt, A., Hosokawa, K., Thomas, S., Yamaguchi, Y., and Hazemann, J., 2013, The World Nuclear Industry Status Report 2013. http://www.worldnuclearreport.org/

- Stirling, A., 1998, On the economics and analysis of diversity, SPRU Electronic Working Paper Series, Paper No 28. 


\section{ANNEXURE A: ATTENDANCE LIST}

Name
Rob
Sue
Keith
Piet
Dennis
Keith
Roseanne
Ricky
Anton
Saliem
Attie

Linda
Yves
Trueman

Thinus

Manisha

Theunis J.

Takanori

Tomas

Seponono

Kelvin

Andrew

Fionah

Remeredzai J Jörg

Kobus

Moti

Philip

Peter

Sajedah

Lethabo

\section{Surname}

Adam

Blaine

Bowen

Bredell

Britz

Campbell

Diab

Dos Santos

Eberhard

Fakir

Ferreira

Fick

Geunon

Goba

Greyling

Gulati

Hanekom

Hayashi

Kåberger

Kekana

Kemm

Kenny

Khathi

Kuhudzai

Lalk

Lawrie

Leto

Lloyd

Lukey

Mahomed

Makhetha

\section{Affiliation}

Aveng

Business Day

Eskom

Independent Nuclear Consultant

EIUG/Arcelor Mittal

Engineering News

ASSAf

ALSTOM Power Service (Pty)Ltd

UCT

WWF

Westinghouse Electric South

Africa (Pty) Ltd

ASSAf

Areva

South African Academy of

Engineering (SAAE)

Group Five Nuclear

Construction Services

WWF

Necsa

Embassy of Japan in South Africa

Chalmers University

Sites

Necsa

University of Pretoria

University of Pretoria

iThemba LABS

Cape Peninsula University of

Technology

Department of Environmental Affairs

Eskom

Necsa 


\section{ANNEXURE A: \\ ATTENDANCE LIST (continue)}

Name

John

Motodi

Christopher

$\mathrm{K}$

Mafika

David

Sunny

Anneline

MZ (Knox)

Dhesigen

Umesh

Lucky

Portia

Phathu

Eric

Johan

Young

Radhika

John

M

Daya

Alan

Amelia

Isaac

Gaopalelwe

Patsy

Dawid

Thuba

Johan
Surname

Marriott

Maserumule

Melane

Mgole

Mkwanazi

Mmakola

Morgan

Morgan

Msebenzi

Naidoo

Natha

Nemakwarani

Nemathithi

Nemushungwa

Njoroge

Otto

Park

Perrot

Prior

Rasweswe

Reddy

Reid

Rennie-Kroon

Salagae

Santswere

Scholtz

Serfontein

Sithole

Slabber

\section{Affiliation}

Consultant, Fellow South African

Academy of Engineering

Necsa

Necsa

Necsa

Transnet SOC Ltd

Department of Science and

Technology

Enerlogy

Southern African Development

Community Secretariat Botswana

Nuclear Industry Association of

South Africa

Water Research Commission

Necsa

Necsa

Alstrom

ASSAf

University of Pretoria

University of Pretoria

Kepco

KESA

Necsa

Necsa

ASSAf

DCD Wind Towers

Necsa

DST

South African Young Nuclear

Professional Society

ASSAf

North-West University

Department of Higher Education and Training

University of Pretoria 


\section{ANNEXURE A: \\ ATTENDANCE LIST (continue)}

\begin{tabular}{|c|c|c|}
\hline Name & Surname & Affiliation \\
\hline Kobus & Smit & Necsa \\
\hline Grovè & Steyn & Meridian Economics \\
\hline Tony & Surridge & $\begin{array}{l}\text { South African National Energy } \\
\text { Development Institute }\end{array}$ \\
\hline Pat & Thema & Mzesi \\
\hline Marie Blanche & Ting & DST \\
\hline Jabulile & Tlhako & Murray \& Roberts Projects \\
\hline Alex & Tsela & $\begin{array}{l}\text { Mzansi Energy Solutions and } \\
\text { Innovations }\end{array}$ \\
\hline Phumzile & Tshelane & Necsa \\
\hline Renate & Venier & ASSAf \\
\hline CJH & Venter & Necsa \\
\hline Henriette & Wagener & ASSAf \\
\hline Nadia & Wietz & ASSAf \\
\hline Harald & Winkler & UCT, ERC \\
\hline Luping & Wu & $\begin{array}{l}\text { State Nuclear Power Technology } \\
\text { Company of China }\end{array}$ \\
\hline Lwandiso & Zamxaka & Eskom \\
\hline Dieter & Zimolong & Necsa \\
\hline Heather & Erasmus & Write Connection, Scribe \\
\hline
\end{tabular}




\section{ANNEXURE B: ACRONYMS}
ASSAf
Academy of Science of South Africa
CAPM
Capital asset pricing model
CCGT
Combined cycle gas turbines
CCS
$\mathrm{CO}_{2}$
CPUT
CSP
DCF
Carbon capture and storage
Carbon dioxide
Cape Peninsula University of Technology
Concentrated solar power
Discount cash flow
DoE
DRC
Department of Energy
DST
Democratic Republic of the Congo
EOCK
Department of Science and Technology
EPR
Economic opportunity cost of capital
EPRI
Evolutionary power reactor
ERC
GDP
GW
Electric Power Research Institute
IAEA
IEP
IPP
IRP
Energy Research Centre
Gross domestic product
Gigawatt
International Atomic Energy Agency
Integrated energy plan
Independent power producer
Integrated Resource Plan
kWh
Kilowatt hour
LCOE
Levelised costs of energy
LNG
MWh
Liquefied natural gas
Megawatt hour
NDP
National Development Plan
Necsa
South African Nuclear Energy Corporation
NERSA
National Energy Regulator of South Africa
NIASA
NPC
NPV
NWU
Nuclear Industry Association of South Africa
National Planning Commission
Net present value
North-West University
OCGT
Open cycle gas turbines 


\section{ANNEXURE B: ACRONYMS (continue)}

OECD Organisation for Economic Co-operation and Development

PPA Power purchase agreement

PV Photovoltaic

SAAE South African Academy of Engineering

SADC Southern African Development Community

SANEDI South African National Energy Development Institute

SNPTC State Nuclear Power Technology Company (of China)

Stats SA Statistics South Africa

TWh per annum Terrawatt hour per annum

UCT University of Cape Town

US United States

WACC Weighted average cost of capital

WWF World Wildlife Foundation 


\section{Notes}




\section{Notes}




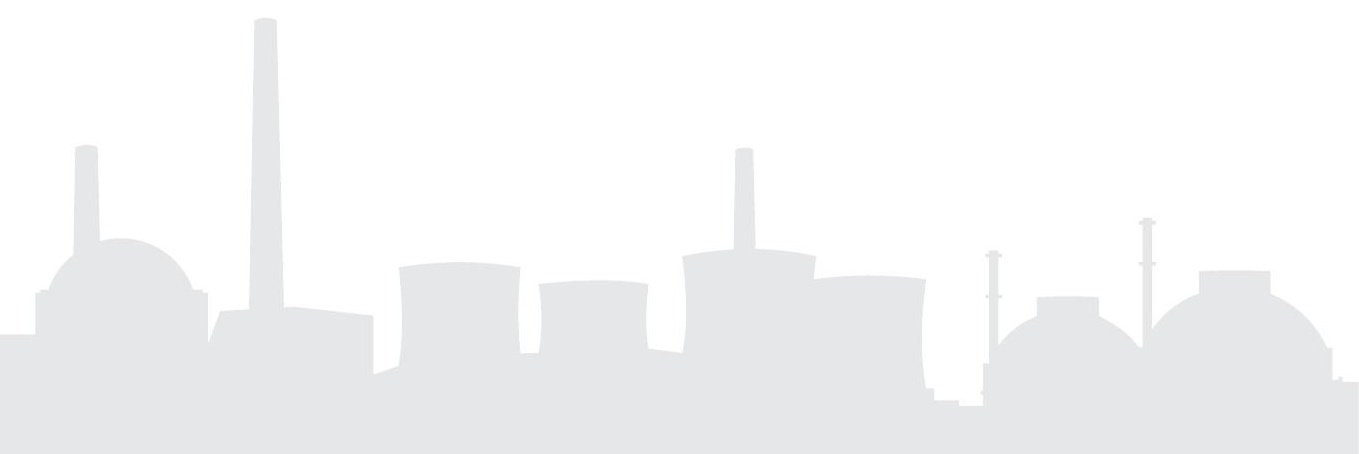



2014

\section{Proceedings of a Symposium on Our Nuclear Future: Delay or Demise?}

\section{Academy of Science of South Africa (ASSAf)}

Academy of Science of South Africa

Academy of Science of South Africa (ASSAf), (2014). Proceedings of a Symposium on Our

Nuclear Future: Delay or Demise? [Online] Available at: DOI http://dx.doi.org/10.17159/assaf/0006 http://hdl.handle.net/20.500.11911/60

Downloaded from ASSAf Research Repository, Academy of Science of South Africa (ASSAf) 